\title{
Dental Caries in European Adults and Senior Citizens 1996-2016: ORCA Saturday Afternoon Symposium in Greifswald, Germany - Part II
}

\author{
Joana Christina Carvalho ${ }^{a} \quad$ Ulrich Schiffner ${ }^{b}$

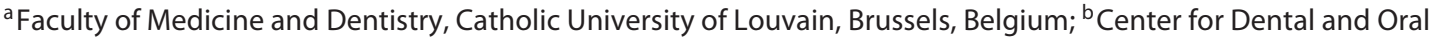 \\ Medicine, University Medical Center Hamburg-Eppendorf, Hamburg, Germany
}

\section{Keywords}

Dental caries · Epidemiology · Adult · Oral health survey ·

Prevalence $\cdot$ Incidence

\begin{abstract}
This review assesses the development of oral health habits and status in European adults (35-44 years old) and senior citizens (65-74 years old) over the period of 1996-2016. There seem to be good opportunities for improving oral health habits by brushing twice daily with fluoride toothpaste among adults, as only $33-85 \%$ reported doing so. Caries experience was extensive among adults ( $\geq 92 \%)$. In adults of 23 countries, the mean DMFT score ranged from 6.6 to 17.6 (median 12.1). In senior citizens of 21 countries, the mean DMFT score varied from 14.7 to 25.5 (median 22.0). Repeated cross-sectional studies on caries trends in adults revealed a reduction of the DMFT value by $20 \%$, referring to country-wide data. Among senior citizens, the corresponding reduction was $13 \%$, with a shift in the DMFT components, i.e., with lower MT and higher FT scores. Edentulousness in the age group of 35- to 44-year-olds started disappearing in Europe from the year 2000, and had been markedly reduced in some countries during the last decade. However, the eradication of edentulousness among 65- to 74-year-olds has not
\end{abstract}

\section{KARGER}

(c) 2018 S. Karger AG, Basel

E-Mail karger@karger.com

www.karger.com/cre yet been reported. Further epidemiological surveys should apply caries diagnostic criteria that, besides representing our contemporary understanding of oral health care, allow comparisons with previous surveys using the WHO criteria. In conclusion, in the last two decades, a decline in caries was observed among European adults, and to a lesser extent among senior citizens. It is expected that the decline in caries will contribute to better oral health of individuals.

두 2018 S. Karger AG, Base

\section{Introduction}

In 1995, the second Saturday Afternoon Symposium on Caries Epidemiology in Europe organized by the European Association for Caries Research took place in Noordwijkerhout, The Netherlands. In this symposium, the prevalence of dental caries in Europe (1990-1995) and the factors influencing caries decline were discussed. The data presented covered children, adolescents, and adults [Marthaler et al., 1996].

In 2014, the third Saturday Afternoon Symposium on Caries Epidemiology in Europe was held in Greifswald, Germany. The present review is based on oral health data on adults and senior citizens - age groups with hitherto 
limited availability of information - collected for the symposium in Greifswald which were further completed with data from the related literature up to 2016.

The aims of this review may be described as follows: (1) to assess the oral health habits and status of adults and senior citizens across Europe; (2) to describe trends in dental caries among adults and senior citizens across Europe; and (3) to comment on the impact of oral health conditions on daily life performances and on the use of clinical caries diagnosis in epidemiological studies.

\section{Subjects and Methods}

In accordance with current recommendations, adults were represented by 35 - to 44 -year-olds and senior citizens by 65 - to 74 -year-olds. These age groups are reference groups recommended by the World Health Organization [WHO, 2013; WHO/CAPP, 2014].

The literature review was performed by means of MEDLINE via PubMed using various combinations of MeSH terms such as dental caries, epidemiology, adult, prevalence, incidence, oral health survey, Europe, caries trends, and DMFT index and complementing this approach by manual search, including reports of national oral health surveys, the WHO/CAPP database [WHO/ CAPP, 2014], and The Oral Health Atlas [FDI World Dental Federation, 2009].

Included were cross-sectional or longitudinal studies of European populations in the age groups of 35-44 or 65-74 years which were representative at the national, regional, or municipal level. A total of 1,086 papers including clinical or nonclinical data were initially selected. Filtering the results in terms of the time frame from January 1, 1996, to December 31, 2014, reduced the number of papers to 558. A complementary search up to December 2016 was carried out, which produced 18 more articles.

Excluded were papers without abstracts as well as papers published in other languages than English, German, Dutch, French, Spanish, or Portuguese. In addition, papers reporting data at the national level were given priority over those reporting at the regional or municipal level, leading to 103 articles. In cases in which multiple papers from the same country were available, those with the more recent years of data collection were chosen. However, more than one paper per country could be selected to gather information about the various oral health indicators included in the present review. Finally, 62 publications were included.

In order to present the oral health habits and status of adults and senior citizens in Europe during the study period, data on oral health indicators that have traditionally been reported in epidemiological surveys were described as follows:

1. Oral health habits, defined as the percentage of adults reporting brushing their teeth twice daily together with the use of fluoride toothpaste

2. Dentition status according to the DMFT index $(\mathrm{D}=$ dentine caries lesion; $\mathrm{M}=$ missing due to caries; $\mathrm{F}=$ filled; $\mathrm{T}=$ tooth) equal to zero, defined as the percentage of adults without caries experience according to the WHO criteria for clinical caries diagnosis [WHO, 2013]

Oral Health in European Adults and Senior Citizens 1996-2016
3. Dentition status according to coronal caries experience, defined as the mean DMFT index and its components in adult and senior citizens

4. Dentition status according to the prevalence of root caries, defined as the percentage of senior citizens with this condition

5. Edentulousness, defined as the percentage of edentulous adult and senior citizens

The data were retrieved from the selected studies and reports and recorded in an Excel file by the authors.

\section{Results}

\section{Oral Health Habits}

Table 1 summarizes studies on oral health habits regarding the frequency of tooth brushing and use of fluoride toothpaste among 35- to 44-year-old European adults. These data were essentially gathered by means of questionnaires from national and municipal surveys published during the period from 1998 to 2016. Between 33 and $81 \%$ of the adults in 9 European countries reported tooth brushing twice daily with fluoride toothpaste [Petersen et al., 2000; Skudutyte-Rysstad and Eriksen, 2007; Chadwick et al., 2009; Tseveenjav et al., 2010; Llodra Calvo, 2012; Schuller et al., 2014; Bottenberg et al., 2015; Calado et al., 2015; Jordan and Micheelis, 2016].

\section{Adults without Caries Experience according to the \\ WHO Criteria for Caries Diagnosis}

The percentage of individuals at the age of 35-44 years with a DMFT index equal to zero in European countries is shown in Table 2. Low percentages ranging from 0 to $8 \%$ were registered for almost all countries included [Vrbic, 2000; Ivanković et al., 2003; Petersen et al., 2004; Hugoson and Koch, 2008; Zitzmann et al., 2008; Pashayev et al., 2011; Llodra Calvo, 2012; Mamai-Homata et al., 2012; Schuller et al., 2014; Bottenberg et al., 2015; Calado et al., 2015; Jordan and Micheelis, 2016], except for Turkey with $24.2 \%$ of adults presenting a DMFT index equal to zero [Gökalp et al., 2010]. These data indicate that the caries prevalence in European adults is high, reaching more than $90 \%$ of the population.

\section{Mean Number of DMFT Scores in Adults}

Twenty-three countries reported mean DMFT scores for the age group of 35- to 44-year-old adults. The mean DMFT scores varied largely between 6.6 and 17.6, as shown in Figure 1. The median of the reported DMFT scores for all countries was 12.1 [Skudutyte et al., 2000; Vrbic, 2000; Menghini et al., 2002; Ivanković et al., 2003; Tubert-Jeannin et al., 2004; Broukal et al., 2006; Madléna 
Table 1. Percentage of 35- to 44-year-old European adults reporting tooth brushing twice daily or more with fluoridated toothpaste by country and year of data collection

\begin{tabular}{llll}
\hline Country (number of subjects) & Year & $\begin{array}{l}\text { Twice daily } \\
\text { tooth brushing }\end{array}$ & Study \\
\hline Lithuania $(n=381)^{*}$ & $1997-1998$ & $33.0 \%$ & Petersen et al., 2000 \\
Finland $(n=2,148)^{*}$ & 2000 & $61.0 \%$ & Tseveenjav et al., 2010 \\
Norway $(n=149)^{* * *}$ & 2003 & $81.0 \%$ & Skudutyte-Rysstad and Eriksen, 2007 \\
England, Northern Ireland, and & & & \\
$\quad$ Wales $(n=6,469)^{*}$ & 2009 & $80.0 \%$ & Chadwick et al., 2009 \\
Spain $(n=512)^{*}$ & 2010 & $73.3 \%$ & Llodra Calvo, 2012 \\
The Netherlands $(n=332)^{* * *}$ & 2013 & $51.0 \%$ & Schuller et al., 2014 \\
Belgium $(n=330)^{*}$ & $2012-2014$ & $52.1 \%$ & Bottenberg et al., 2015 \\
Portugal $(n=1,296)^{*}$ & $2012-2014$ & $68.7 \%$ & Calado et al., 2015 \\
Germany $(n=966)^{*}$ & 2014 & $80.3 \%$ & Jordan and Micheelis, 2016 \\
\hline
\end{tabular}

In Norway, only 35-year-olds were included. In England, Northern Ireland, and Wales, the data refer to adults. * National oral health survey. ${ }^{* * *}$ Municipal oral health survey.

Table 2. Percentage of 35- to 44-year-old European adults without caries experience according to the WHO criteria for clinical caries diagnosis

\begin{tabular}{llll}
\hline Country & Year & DMFT =0, \% & Study \\
\hline Bosnia and Herzegovina** & 1997 & 2.0 & Ivanković et al., 2003 \\
Slovenia* & 1997 & 0.0 & Vrbic, 2000 \\
Denmark* & 2000 & 0.1 & Petersen et al., 2004 \\
Switzerland* & 2002 & 0.4 & Zitzmann et al., 2008 \\
Sweden*** & 2003 & 8.0 & Hugoson and Koch, 2008 \\
Turkey* & $2004-2005$ & 24.2 & Gökalp et al., 2010 \\
Greece* & 2005 & 0.2 & Mamai-Homata et al., 2012 \\
Azerbaijan* & 2006 & 1.6 & Pashayev et al., 2011 \\
Spain** & 2010 & 8.2 & Llodra Calvo, 2012 \\
The Netherlands*** & 2013 & 0.6 & Schuller et al., 2014 \\
Belgium* & $2012-2014$ & 4.6 & Bottenberg et al., 2015 \\
Portugal* & $2012-2014$ & 2.5 & Calado et al., 2015 \\
Germany* & 2014 & 2.5 & Jordan and Micheelis, 2016 \\
\hline
\end{tabular}

In Sweden, the data refer to 30 -year-olds. ${ }^{*}$ National oral health survey. ${ }^{* *}$ Regional oral health survey. *** Municipal oral health survey.

et al., 2008; Suominen-Taipale et al., 2008; Gökalp et al., 2010; Kuzmina et al., 2010; Holst and Schuller, 2011; Pashayev et al., 2011; Yudina et al., 2011; Damyanov et al., 2012; Llodra Calvo, 2012; Mamai-Homata et al., 2012; Kongstad et al., 2013; Bernabé and Sheiham, 2014; Schuller et al., 2014; Bottenberg et al., 2015; Calado et al., 2015; Jordan and Micheelis, 2016; Arrica et al., 2017].

Even though there was variation in the year of examination and the methodology applied, the WHO criteria for caries diagnosis were used in all surveys. Filled teeth (FT) represented the largest component of the mean
DMFT index in the majority of the countries. In contrast, the proportion of missing teeth (MT) was the largest component of the mean DMFT index in Azerbaijan [Pashayev et al., 2011], Belarus [Yudina et al., 2011], Hungary [Madléna et al., 2008], Russia [Kuzmina et al., 2010], and Turkey [Gökalp et al., 2010].

\section{Mean Number of DMFT Scores in Senior Citizens}

Figure 2 illustrates the mean DMFT scores among 65to 74-year-old senior citizens, which varied largely between the 20 countries included, ranging from 14.6 to 
Fig. 1. Mean number of decayed, missing, and filled teeth (DMFT) in 35- to 44-yearold European adults.

Fig. 2. Mean number of decayed, missing, and filled teeth (DMFT) in 65- to 74-yearold European senior citizens.
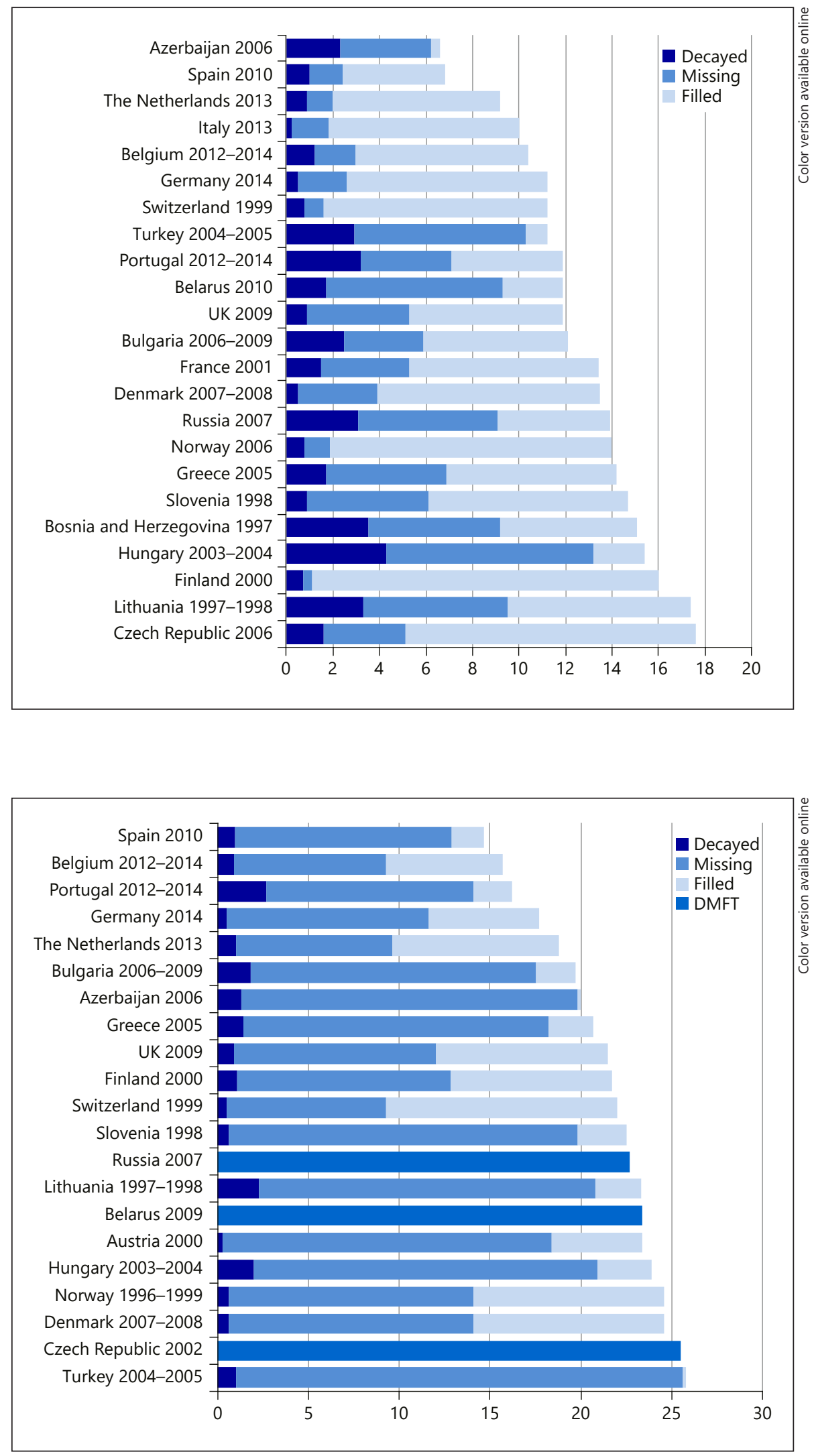
Fig. 3. Prevalence of edentulousness among 65- to 74-year-old senior citizens in Europe.

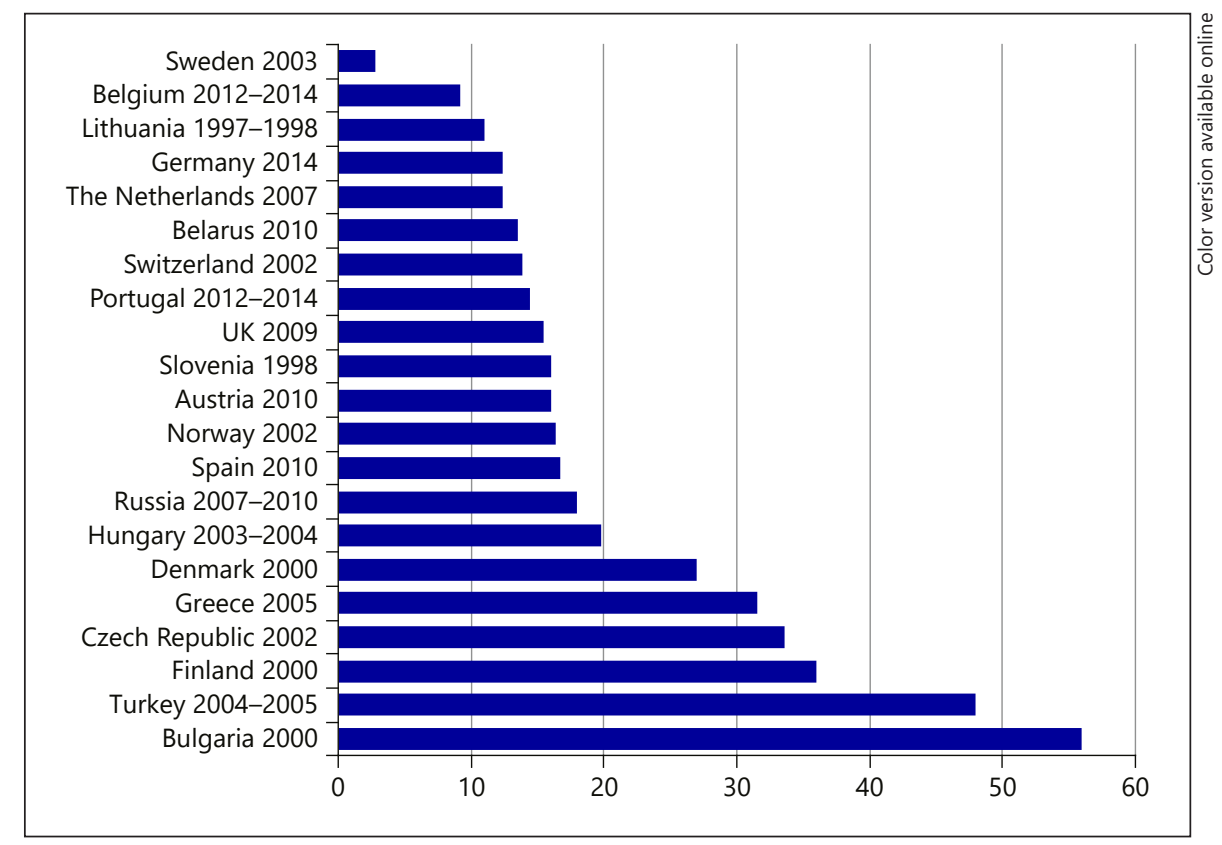

25.8 [Skudutyte et al., 2000; Vrbic, 2000; Menghini et al., 2002; Städtler et al., 2002; Broukal et al., 2003; Henriksen et al., 2004; Madléna et al., 2008; Suominen-Taipale et al., 2008; Gökalp et al., 2010; Janushevich et al., 2010; Pashayev et al., 2011; Tserakhava et al., 2011; Damyanov et al., 2012; Llodra Calvo, 2012; Mamai-Homata et al., 2012; Kongstad et al., 2013; Bernabé and Sheiham, 2014; Schuller et al., 2014; Bottenberg et al., 2015; Jordan and Micheelis, 2016]. For this age group, MT represented the largest component of the DMFT index for all countries, except for Switzerland and the Netherlands, where FT were the largest component [Menghini et al., 2002; Schuller et al., 2014]. The median of the DMFT scores of all countries was 22.0.

The prevalence of individuals with root caries in the senior age group turned out to be less frequently reported in the current literature, with the lowest value being $14.4 \%$ in Spain [Llodra Calvo, 2012], followed by $24.0 \%$ in Belgium [Bottenberg et al., 2015], 28\% in Germany [Jordan and Micheelis, 2016], 28.4\% in Turkey [Gökalp et al., 2010], and 38.3\% in Greece [Mamai-Homata et al., 2012].

\section{Edentulousness in Adults and Senior Citizens}

From the year 2000 onwards, edentulousness has no longer been observed in the age group of 35- to 44-yearold adults in some European countries such as Denmark [Petersen et al., 2004], Sweden [Hugoson and Koch, 2008], England [Steele et al., 2011], and Spain [Llodra
Calvo, 2012]. Similarly, in other countries the prevalence of edentulousness was very low at $0.2-3 \%$, suggesting that this condition is disappearing in Lithuania [Skudutyte et al., 2000], the Czech Republic [Broukal et al., 2006], Finland [Suominen-Taipale et al., 2008], Switzerland [Zitzmann et al., 2008], Norway [Holst, 2008], Hungary [Madléna et al., 2008], the Netherlands [Schuller, 2009], Turkey [Gökalp et al., 2010], Greece [Mamai-Homata et al., 2012], Belgium [Bottenberg et al., 2015], Portugal [Calado et al., 2015], and Germany [Jordan and Micheelis, 2016].

On the other hand, in the age group of 65- to 74-yearolds, the situation is quite dissimilar, according to the data reported from 21 countries (Fig. 3). The percentage of edentulous senior citizens varies considerably between the European countries. The lowest percentage was found in Sweden (2.8\%) [Hugoson and Koch, 2008]. In contrast, in Greece, Finland, Turkey, and Bulgaria, more than onethird of the 65- to 74-year-old seniors are edentulous [Suominen-Taipale et al., 2008; Gökalp et al., 2010; Damyanov et al., 2012; Mamai-Homata et al., 2012].

\section{Caries Trends in Cross-Sectional Studies in Adults and Senior Citizens}

Repeated cross-sectional studies on caries trends in 35 - to 44-year-old adults with a minimum interval of 4 years between the surveys were identified for 13 European countries, as shown in Figure 4. Most of the coun- 
Fig. 4. Repeated cross-sectional studies on caries trends in Europe: mean decayed, missing, and filled teeth (DMFT) scores in 35 - to 44-year-old adults.

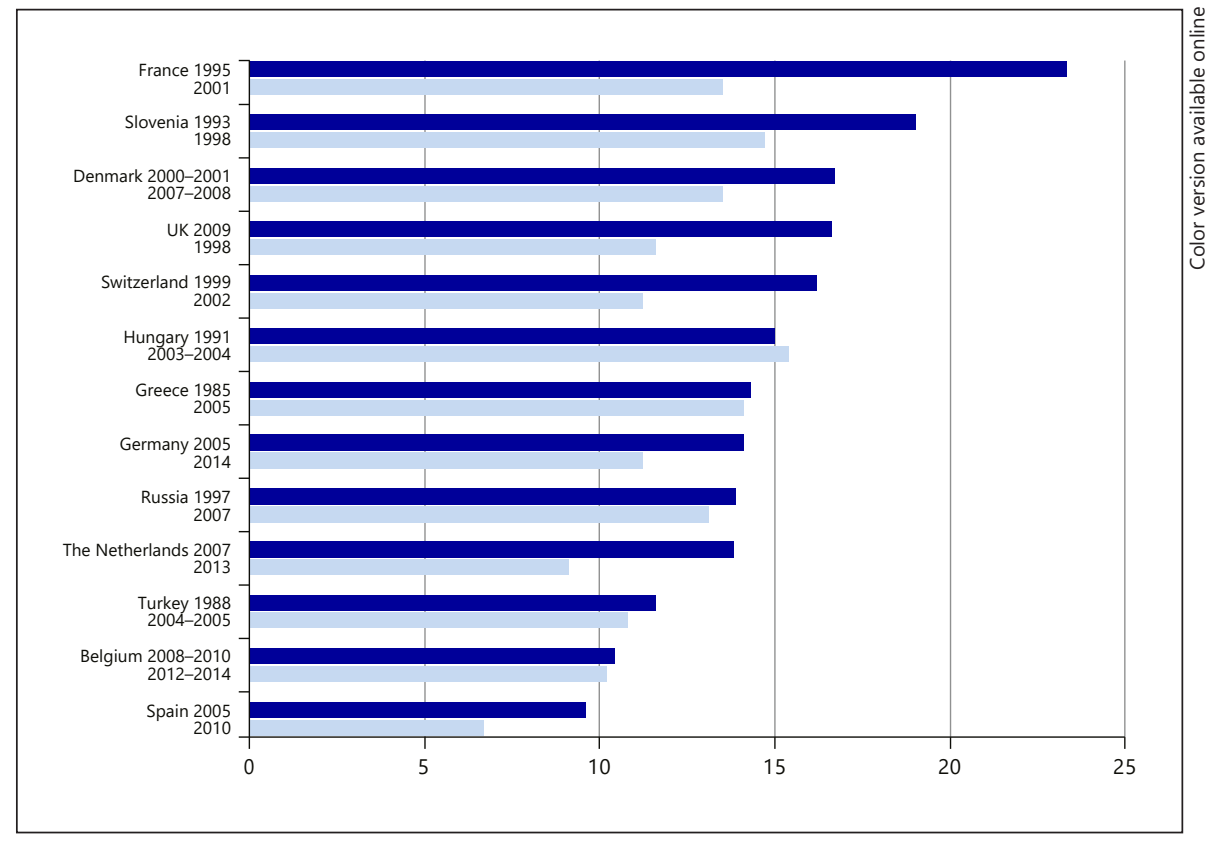

tries showed a decline in caries, as observed in France [Bourgeois et al., 1998; Tubert-Jeannin et al., 2004], Slovenia [Vrbic, 2000], Spain [Llodra Calvo, 2012], Denmark [Krustrup and Petersen, 2007; Kongstad et al., 2013], Russia [Janushevich et al., 2010], the UK [Bernabé and Sheiham, 2014], Switzerland [Menghini et al., 2002], Germany [Schiffner et al., 2005; Jordan and Micheelis, 2016], Hungary [Madléna et al., 2008], Turkey [Gökalp et al., 2010], and the Netherlands [Schuller et al., 2014]. This decline was remarkable in Spain, with a mean DMFT score of 6.7 [Llodra Calvo, 2012]. However, a decline in caries was observed neither in Greece between 1985 and 2005 [Mamai-Homata et al., 2012] nor in Belgium between 2008 and 2012 [Bottenberg et al., 2015].

In addition, a study on caries trends in 35-year-old Norwegians showed a decline from 14.8 in 1993 to 11.7 in 2003 [Skudutyte-Rysstad and Eriksen, 2007]. Similarly, studies carried out in Gothenburg, Sweden, in 1993 and 2003 among age groups of 30- and 40-year-olds also showed a decline in mean DFT scores from 11.8 to 7.8 and from 16.3 to 11.5, respectively [Hugoson and Koch, 2008].

Publications from 12 countries provided information on caries trends in 65- to 74-year-old senior citizens. Figure 5 illustrates the decline in caries observed in Hungary [Madléna et al., 2008], Slovenia [Vrbic, 2000], Austria [Bourgeois et al., 1998; Städtler et al., 2002], Belarus [Bourgeois et al., 1998; Tserakhava et al., 2011], Germany [Schiffner et al., 2009; Jordan and Micheelis, 2016], and the Netherlands [Schuller et al., 2014]. The decline was somewhat limited in the Czech Republic [Bourgeois et al., 1998; Broukal et al., 2002], Denmark [Krustrup and Petersen, 2002; Kongstad et al., 2013], Switzerland [Menghini et al., 2002], Spain [Llodra Calvo, 2012], and Belgium [Bottenberg et al., 2015], whereas a slight increase was reported for Russia [Janushevich et al., 2010].

Moreover, studies carried out in Gothenburg, Sweden, among age groups of 60- and 70-year-olds showed mean DFT scores of 14.1 and 15.8 (1993) and of 12.3 and 15.3 (2003), respectively [Hugoson and Koch, 2008].

\section{Longitudinal Studies in Adults and Senior Citizens}

In Slovenia, a longitudinal study on caries trends was carried out from 1987 to 1997 in 35- to 44-year-old adults $(n=100)$ and 65 - to 74-year-old seniors $(n=65)$. The mean DMFT index in the adults increased from 17.3 \pm 5.0 to $19.5 \pm 5.0$, whereas in the seniors the increase was from $19.5 \pm 4.3$ to $24.6 \pm 6.5$ during the same period [KovačKavčič and Skalerič, 2001]. However, a comparison between the surveys of 1987 and 1997 indicated a marked decline in the mean number of decayed teeth and a slight increase in the mean number of filled teeth in adults. The mean number of missing teeth increased between the surveys in the adults and senior citizens.

More recently, a longitudinal study carried out on Norwegian regular dental service attendees was published. The paper was based on data collected annually 
Fig. 5. Repeated cross-sectional studies on caries trends in Europe: mean decayed, missing, and filled teeth (DMFT) scores in 65- to 74-year-old senior citizens.

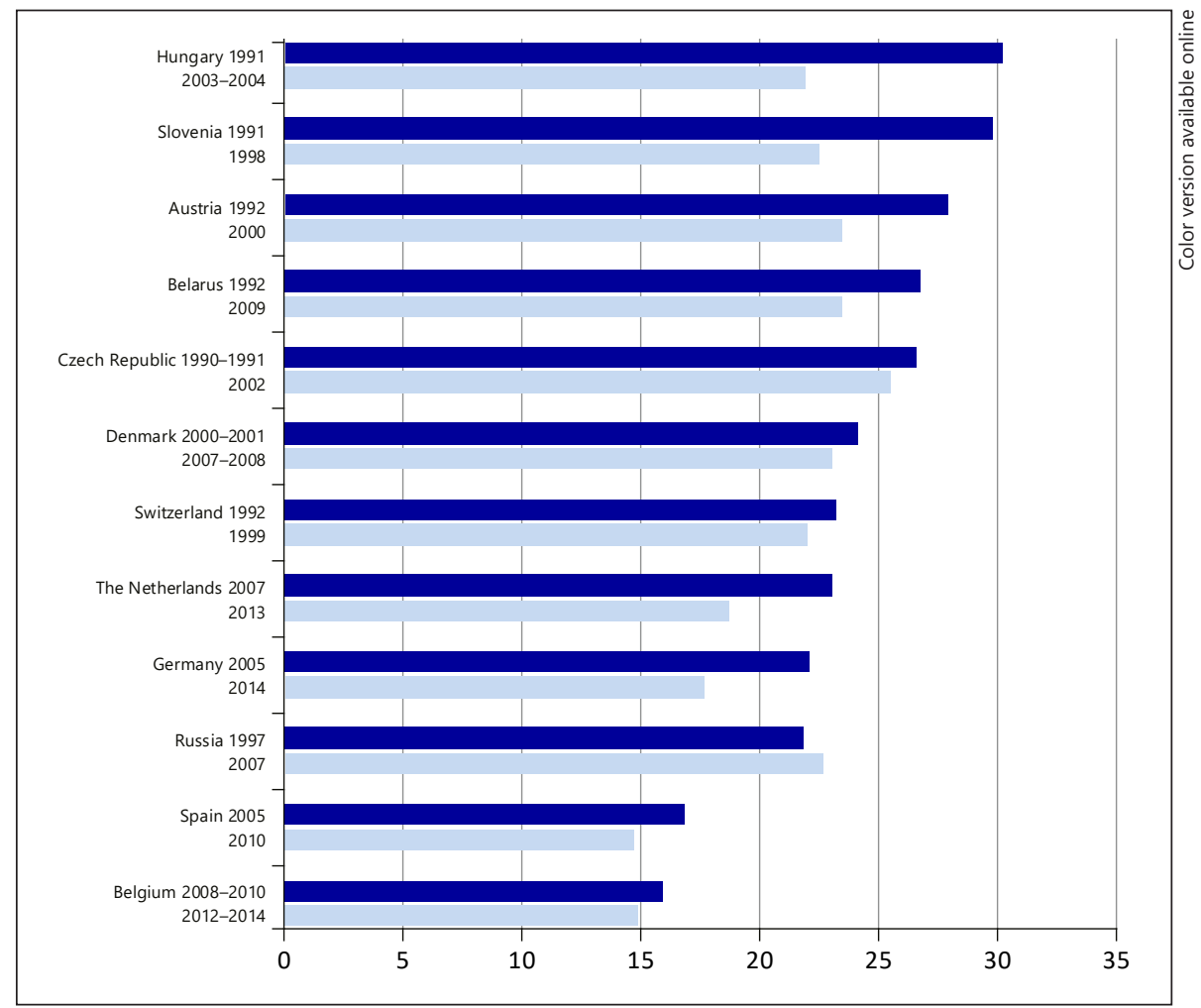

from 2003 to 2012 in the public dental service [Dobloug and Grytten, 2015]. In 2012, 33- to 42-year-old individuals $(n=1,453)$ and 63 - to 72 -year-old persons $(n=888)$ had a mean DMFT index of $10.2 \pm 0.1$ and $20.4 \pm 0.2$, respectively. Both cohorts showed a fairly similar pattern concerning caries incidence. Nearly $90 \%$ of the individuals had no new caries during the first 5 observation years. After 8 years, $48.5 \%$ of the adults had no new caries, in comparison with $46.0 \%$ of the seniors. These figures dropped to 12.0 and $10.7 \%$, respectively, by the end of the study.

Commentary on the Impact of Oral Health Conditions on Daily Life Performances

Traditionally, oral health status has been measured through clinical assessments of the absence or presence of diseases as well as by the assessment of short- and long-term treatment outcomes [Locker, 2004]. Currently, this approach is considered limited due to growing recognition that nonclinical assessments such as oral health-related quality of life are important measures of an individual's oral health, daily functioning, and wellbeing [Sheiham and Steele, 2001; Locker and Allen, 2007].
The appraisal of oral health-related quality of life has increasingly gained attention in observational cross-sectional and longitudinal epidemiological studies [Tsakos et al., 2012; Carvalho et al., 2015]. National oral health surveys such as those carried out in Finland [SuominenTaipale et al., 2008], Spain [Llodra Calvo, 2012], the Netherlands [Schuller et al., 2014], Belgium [Bottenberg et al., 2015], and Portugal [Calado et al., 2015] assessed the impact of oral health conditions on the oral health-related quality of life of their populations. In these surveys, the instrument used to measure the impact on oral healthrelated quality of life was the validated abridged Oral Health Impact Profile-14 (OHIP-14) [Slade, 1997]. The OHIP-14 measures the adverse impact of oral health conditions related to the teeth, mouth, or dentures on physical, psychological, and social dimensions [Locker, 2004]. The questions are answered on an ordinal scale as "never," "hardly ever," "occasionally," "fairly often," or "very often."

The percentages of adults and senior citizens who reported adverse effects on their oral health-related quality of life occasionally or more often were $36 \%$ and $28 \%$, respectively, in Finland [Suominen-Taipale et al., 2008] and $26.1 \%$ and $22.6 \%$ in Spain [Llodra Calvo, 2012]. In Portu- 
gal [Calado et al., 2015], the corresponding figures were $25.2 \%$ and $25.7 \%$, respectively, but only seven questions of the OHIP-14 were included in the survey. In Belgium, the median OHIP-14 score was calculated as 0.7 (range 0.0-52.0) for adults and 1.8 (range 0.0-50.0) for senior citizens [Bottenberg et al., 2015]. A larger percentage of edentulous (52\%) than of dentate (33\%) subjects reported having had at least one adverse effect on their oral healthrelated quality of life [Suominen-Taipale et al., 2008]. A further inclusion and dissemination of findings on oral health-related quality of life of adults and seniors is desirable.

\section{Commentary on Clinical Caries Diagnosis in Epidemiological Studies}

Over the last two decades, in epidemiological studies there has been a growing interest in diagnosing the caries process according to its activity and severity - particularly in clinical stages of development that precede cavitation. The rationale has been to obtain a more accurate estimate of the caries prevalence and treatment needs, in addition to obtaining a scientific basis for treatment decisions and management of the caries process at the population level [Carvalho et al., 2001, 2015; Hugoson and Koch, 2008; Ismail et al., 2009; Machiulskiene and Carvalho, 2018]. This reasoning may equally be applied to oral health care of individuals in clinical practice as well as of populations in public health services.

On the other hand, the implementation and dissemination of the ORCA Cariology Curriculum in Dental Schools and Dental Associations around the world [Schulte et al., 2011] offer an extra opportunity for training dental students in caries diagnosis and its application in epidemiological surveys. In today's scenario, an increasing number of dental schools around the world have been updating the training of their students in caries diagnosis. In the future, the use of clinical caries diagnostic criteria assessing the activity and severity of caries lesions in epidemiological studies will become a natural continuation of the university training. Researchers and policymakers questioning the appropriateness of applying such caries diagnostic criteria under field conditions, the reliability of these criteria, and the extra time required and their influence on caries outcomes should be informed that these aspects have already been investigated and that they are no cause for concern [Carvalho and Mestrinho, 2014]. Moreover, such caries diagnostic criteria, besides representing our current understanding of the caries process, allow comparisons with previous surveys using the WHO criteria.

Oral Health in European Adults and Senior Citizens 1996-2016

\section{Discussion}

Reviewing the caries prevalence in adults and senior citizens in Europe has disclosed challenges, as there is much and diverse information available on some countries but only scant information on other countries. The modalities of data acquisition differ between countries, as well as some target variables and the presentation of the results. For these reasons and due to the substantial period covered in data collection, encompassing the period from 1996 to 2016, comparisons of the caries prevalence and its consequences between European countries are not straightforward.

Grouping the data side by side, as shown in Tables 1 and 2 together with Figures 1-3, has only a descriptive purpose and does not aim at direct comparisons between European countries. However, the data presented Figures 4 and 5 are sufficient to outline changes in caries prevalence. Most of these data have been used to provide scientifically based information to support political decisions by health authorities in individual countries.

Some European countries have implemented regular national collections of oral health data which have been published in papers and reports. All national oral health surveys mentioned in this review were well designed and had sound methodologies including representative random sampling and calibration of examiners, leading to good data quality. Although methodological differences between these surveys were observed, the main oral health indicators could easily be retrieved from these reports [Petersen et al., 2000; Skudutyte-Rysstad and Eriksen, 2007; Suominen-Taipale et al., 2008; Chadwick et al., 2009; Tseveenjav et al., 2010; Llodra Calvo, 2012; Bottenberg et al., 2015; Calado et al., 2015; Jordan and Micheelis, 2016]. Nevertheless, a more refined harmonization of data collection at the national level between countries could be set as a goal to be achieved in the future.

With respect to countries with information at the regional or municipal level, efforts were made to present the most representative and recent data [Schuller et al., 2014]. It should be borne in mind that the WHO recommendation from 2013 to implement oral health data collection at the national level may cause difficulties for some countries due to the associated extensive organizational requirements and costs. Data from surveys at the regional or even at the municipal level were included in this review. Taken together, it shows that dental caries still is a common disease in adults.

With regard to home-based oral health care as well as dental caries and its consequences for adults and senior

Caries Res 2019;53:242-252 
citizens, there are large differences between the European countries. Extreme values - i.e., outliers - shown in the present review should be interpreted with caution and be confirmed by further studies.

Dental caries is considered as a behavior-dependent disease affected by oral hygiene measures. Since regular brushing with fluoride toothpaste has been shown to be strongly related to lower caries experience [Figuero et al., 2017], there is support for the rationale behind the collection of this indicator in the context of this review. Given the strong evidence that brushing with fluoride toothpaste twice a day controls the rate of caries progression more effectively than does brushing only once a day [Kumar et al., 2016], there seem to be good opportunities for improving oral health further, as only $33-85 \%$ of the adults in some European countries stated that they followed this recommendation (Table 1).

The present review reveals DMFT values for adults ranging from 6.6 to 17.6. In comparison, the review published by Marthaler et al. [1996] exhibited a range of mean DMFT values between 13.4 and 20.8, which clearly indicates a decline in caries. More important information can be derived from intra-country comparisons between repeated cross-sectional studies. Most of these comparisons reveal a distinct decline in caries among adults, with markedly lower caries experiences in the latest comparisons. A closer look at the DMFT changes in countries that have conducted repeated surveys (Fig. 4) shows that the caries experience ranged from 9.6 to 23.3 in the first studies (mean 15.0, median 14.3), while in the follow-up studies a range from 6.7 to 15.4 was observed (mean 11.9, median 11.6). This suggests a reduction of the DMFT value by $20 \%$ referring to country-wide data.

An interesting part of this review shows a trend in caries experience in 65- to 74-year-old senior citizens which was less marked that that of 35- to 44-year-old adults. While the mean DMFT scores varied from 15.9 to 30.2 in the first surveys (mean 24.0, median 23.7), they turned out to be between 14.7 and 25.5 (mean 20.9, median 22.3) in the later surveys, corresponding to a reduction by $13 \%$. Probably even more important than the reduction in DMFT is the shift in DMFT components, exhibiting lower MT scores but higher FT scores. This indicates a paradigm shift towards restorative rather than extraction therapy and should have considerable consequences for dental health service research in the future.

Although repeated cross-sectional surveys provide valuable conclusions regarding trends, they are limited with respect to the identification of specific factors associated with improvements in oral health. It is acknowl- edged that longitudinal studies on caries prevalence and experience are rarely carried out in adult and senior populations [Kovač-Kavčič and Skalerič, 2001; Dobloug and Grytten, 2015]. Major drawbacks of longitudinal studies are the loss of subjects to follow-up and organizational requirements. These limit the feasibility of longitudinal epidemiological studies, which is why cross-sectional studies are the preferred option for national oral health surveys in many countries.

Edentulousness may be seen as a robust indicator for the caries process and its consequences in adult and senior populations. The data showed a substantial gain in oral health also with respect to this indicator. According to our review, edentulousness in the age group of 35- to 44-year-olds started disappearing from the year 2000 [Petersen et al., 2004; Hugoson and Koch, 2008; Llodra Calvo, 2012] and has been diminished in some countries during the last decade, and it might be expected to disappear in more countries in the near future.

However, in the age group of 65- to 74-year-olds, the eradication of edentulousness was not yet reported in any of the countries (Fig. 4). This indicates that the eradication of this condition among seniors in European countries is unlikely to occur in the short term, which is in agreement with findings by Fure [2003] and Müller et al. [2007].

In the present review, all included studies used the WHO criteria for caries diagnosis. Recently, clinical caries diagnostic criteria were revisited to reflect the dynamics of the disease and accordingly to provide a solid basis for subsequent treatment decisions and for further monitoring of dental health of individuals and populations. The use of clinical caries diagnostic criteria in research, in clinical practice, and public health services should be guided by the best available scientific evidence and be universally applicable in all these fields. In this context, the use of caries diagnostic criteria that assess the activity and severity of early caries lesions was recommended, as these favor the best clinical practice directed towards nonoperative interventions [Machiulskiene and Carvalho, 2018]. Epidemiological studies start to report noncavitated active lesions in adults and senior citizens [Jordan and Micheelis, 2016]. However, further epidemiological surveys should also allow for comparisons with previous surveys that used the WHO criteria. Of interest to adults and senior citizens is the diagnosis of coronal as well as root caries in early stages of development. The present review showed that root caries is underreported in the literature.

In conclusion, in the last two decades a decline in caries has been observed in European adults and, to a minor ex- 
tent, in senior citizens. It is expected that this decline may contribute to better oral health in both age groups in the future. In addition to these positive consequences for the European populations, important changes to the dental profession as well as the health systems can be expected.

\section{Statement of Ethics}

No ethical approval was required for this study, since it was based on the secondary analysis of available data already published in the literature.

\section{Disclosure Statement}

The authors have no conflict of interest to declare.

\section{Author Contributions}

J.C.C. designed the review; both authors collected the data and wrote the manuscript.

\section{References}

Arrica M, Carta G, Cocco F, Cagetti MG, Campus G, Ierardo G, Ottolenghi L, Sale S, Strohmenger L: Does a social/behavioural gradient in dental health exist among adults? A cross-sectional study. J Int Med Res 2017;45:451-461.

Bernabé E, Sheiham A: Age, period and cohort trends in caries of permanent teeth in four developed countries. Am J Public Health 2014; 104:e115-e121.

Bottenberg P, Carvalho JC, Declerck D, Declerck K, De Vos E, Vanden Abbeele A, Van Nieuwenhuysen JP, Vanobbergen J: Rapport final du projet: Système d'enregistrement et de surveillance de la santé bucco-dentaire de la population belge 2012-2014. INAMI, 2015. http://www.inami.fgov.be/fr/publications/ Pages/etudes-sante-bucco-dentaire-belge. aspx\#.VfcfiPboudI (assessed December 2017).

Bourgeois D, Nihtila A, Mersel A: Prevalence of caries and edentulousness among 65-74-yearolds in Europe. Bull World Health Organ 1998;76:413-417.

Broukal Z, Mrklas L, Krejsa O, Mazánková V, Pázlerová V: Oral health status of elderly in the Czech Republic 2002 (abstract). Community Dent Health 2003;20:181.

Broukal Z, Mrklas L, Krejsa O, Mazánková V, Pázlerová V: Oral health of selected age categories of the population of Czech Republic. WHO/ CAPP, 2014. www.uzis.cz/system/files/oralzdr2006.pdf.

Calado R, Ferreira CS, Nogueira P, Melo P: III estudo Nacional de Prevalência de Doenças Orais. Direção Geral da Saúde, Relatório, 2015. https://www.dgs.pt/documentos-epublicacoes/iii-estudo-nacional-de-prevalencia-das-doencas-orais.aspx.

Carvalho JC, Mestrinho HD: Diagnosing noncavitated lesions in epidemiological studies: practical and scientific considerations. Braz Oral Res 2014;28(Spec No):1-7.

Carvalho JC, Mestrinho HD, Stevens S, van Wiik AJ: Do oral health conditions adversely impact young adults? Caries Res 2015;49:266274.
Carvalho JC, Van Nieuwenhuysen JP, D'Hoore $\mathrm{W}$ : The decline in dental caries among Belgian children between 1983 and 1998. Community Dent Oral Epidemiol 2001;29:55-61.

Chadwick B, White D, Lader D, Pitts N: Preventive behaviour and risks to oral health - a report from the Adult Dental Health Survey 2009. http://www.hscic.gov.uk/catalogue/ PUB01086/adul-dent-heal-surv-summthem-the5-2009-rep7.pdf (assessed December 2016).

Damyanov ND, Witter DJ, Bronkhorst EM, Creugers NHJ: Dental status and associated factors in a dentate adult population in Bulgaria: a cross-sectional survey. Int J Dent 2012;2012:578401.

Dobloug A, Grytten J: A ten-year longitudinal study of caries among patients aged 14-72 years in Norway. Caries Res 2015;49:384-389.

FDI - World Dental Federation: The Oral Health Atlas 2009, pp. 96-107. https://www.fdiworlddental.org/resources/oral-health-atlas/ oral-health-atlas-2009 (assessed December 2016).

Figuero E, Nóbrega DF, García-Gargallo M, Tenuta LM, Herrera D, Carvalho JC: Mechanical and chemical plaque control in the simultaneous management of gingivitis and caries: a systematic review. J Clin Periodontol 2017; 44(suppl 18):S116-S134

Fure S: Ten-year incidence of tooth loss and dental caries in elderly Swedish individuals. Caries Res 2003;37:462-469.

Gökalp S, Guciz Doğan B, Tekçiçek M, Berberoğlu A, Ünlüer S: National survey of oral health status of children and adults in Turkey. Community Dent Health 2010;27:12-17.

Henriksen BM, Ambjørnsen E, Axéll T: Dental caries among the elderly in Norway. Acta Odontol Scand 2004;62:75-81.

Holst D: Oral health equality during 30 years in Norway. Community Dent Oral Epidemiol 2008;36:326-334
Holst D, Schuller AA: Equality in adults' oral health in Norway. Cohort and cross-sectional results over 33 years. Community Dent Oral Epidemiol 2011;39:488-497.

Hugoson A, Koch G: Thirty year trends in the prevalence and distribution of dental caries in Swedish adults (1973-2003). Swed Dent J 2008;32:57-67.

Ismail AI, Lim S, Sohn W, Willem JM: Predictors of dental caries progression in primary teeth. J Dent Res 2009;88:270-275.

Ivanković A, Lukić IK, Ivanković Z, Radić A, Vukić I, Simić A: Dental caries in postwar Bosnia and Herzegovina. Community Dent Oral Epidemiol 2003;31:100-104.

Janushevich OO, Fabrikant EG, Kazakov AS: Systems for the provision of oral health care in the Black Sea countries - Part 5: the Russian Federation. OHDMBSC 2010;9:59-62.

Jordan AR, Micheelis W: The Fifth German Oral Health Study (DMS V). Institute of German Dentists. Köln, Deutscher Zahnaerzteverlag DÄV, 2016

Kongstad J, Ekstrand K, Qvist V, Christensen LB, Cortsen B, Grønbæk M, Holm-Pedersen P, Holmstrup P, Bardow A, Twetman S, Fiehn $\mathrm{N}$-E: Findings from the oral health study of the Danish Health Examination Survey 20072008. Acta Odontol Scand 2013;71:1560-1569.

Kovač-Kavčič M, Skalerič U: The change of DMFT counts in Slovenia. Caries Res 2001; 35:247-251.

Krustrup U, Petersen PE: Dental caries prevalence among adults in Denmark - the impact of socio-demographic factors and use of oral health services. Community Dent Health 2007;24:225-232.

Kumar S, Tadakamadla J, Johnson NW: Effect of toothbrushing frequency on incidence and increment of dental caries: a systematic review and meta-analysis. J Dent Res 2016;95: 1230-1236.

Kuzmina I, Janushevich O, Smirnova T, Kuznetvov P: Caries prevalence among 35-44-yearolds in Russia. J Dent Res 2010;89(Spec Iss B):abstract\#4142. 
Llodra Calvo JC: Encuesta de salud oral en Espanã 2010. RCOE 2012;17:13-41.

Locker D: Oral health and quality of life. Oral Health Prev Dent 2004;1:247-253.

Locker D, Allen F: What do measures of "oral health related quality of life" measure? Community Dent Oral Epidemiol 2007;35:401411.

Machiulskiene V, Carvalho JC: Clinical diagnosis of dental caries in the 21st century: Introductory Paper - ORCA Saturday Afternoon Symposium, 2016. Caries Res 2018;52:387-391.

Madléna M, Hermann P, Jáhn M, Fejérdy P: Caries prevalence and tooth loss in Hungarian adult population: results of a national survey. BMC Public Health 2008;8:364.

Mamai-Homata E, Topitsoglou V, Oulis C, Margaritis V, Polychronopoulou A: Risk indicators of coronal and root caries in Greek middle aged adults and senior citizens. BMC Public Health 2012;12:484.

Marthaler TM, O'Mullane DM, Vrbic V: The prevalence of dental caries in Europe 1990 1995. ORCA Saturday Afternoon Symposium 1995. Caries Res 1996;30:237-255.

Menghini G, Steiner M, Helfenstein U, Imfeld C, Brodowski D, Hoyer C, Hofmann B, Furrer R, Imfeld T: Zahngesundheit von Erwachsenen im Kanton Zürich. Schweiz Monatsschr Zahnmed 2002;112:708-717.

Müller F, Nacharro M, Carlsson GE: What are the prevalence and incidence of tooth loss in the adult and elderly population in Europe? Clin Oral Impl Res 2007;18:2-14.

Pashayev AC, Mammadov FU, Huseinova ST: An investigation into the prevalence of dental caries and its treatment among the adult population with low socio-economic status in Baku, Azerbaijan. OHDM 2011;10:7-12.

Petersen PE, Aleksejuniene J, Christensen LB, Eriksen HM, Kalo I: Oral health behavior and attitudes of adults in Lithuania. Acta Odontol Scand 2000;58:243-248.
Petersen PE, Kjøller M, Christensen LB, Krustrup U: Changing dentate status of adults, use of dental health services, and achievement of national dental health goals in Denmark by the year 2000. J Public Health Dent 2004;64:127135.

Schiffner U, Hoffmann T, Kerschbaum T, Micheelis W: Oral health in German children, adolescents, adults and senior citizens in 2005. Community Dent Health 2005;26:1822.

Schuller AA: Mondgezondheid volwassenen 2007. Leiden, TNO-rapport, 2009.

Schuller AA, van Kempen I, Vermarie E, Poorterman J, Verlinden A, Hofstetter H, Verrips E: Gebit Fit? Een onderzoek naar de mondgezondheid en het tandheelkundig preventief gedrag van volwassenen in Nederland in 2013. Leiden, TNO-rapport, 2014.

Schulte AG, Pitts NB, Huysmans MC, Splieth C, Buchalla W: European core curriculum in cariology for undergraduate dental students. Caries Res 2011;45:336-345

Sheiham A, Steele J: Does the condition of the mouth and teeth affect the ability to eat certain foods, nutrient and dietary intake and nutritional status amongst older people? Public Health Nutr 2001;4:797-803.

Skudutyte R, Aleksejuniene J, Eriksen HM: Dental caries in adult Lithuanians: Acta Odontol Scand 2000;58:143-147.

Skudutyte-Rysstad R, Eriksen HM: Changes in caries experience among 35-year-old Oslo citizens, 1973-2003. Acta Odontol Scand 2007; 65:72-77.

Slade GD: Derivation and validation of a shortform Oral Health Impact Profile. Community Dent Oral Epidemiol 1997;25:284-290.

Städtler P, Bodenwinkler A, Sax G: Caries prevalence in a 35-44 and 65-74-year-old Austrian population (abstract). Caries Res 2002;36: 207.
Steele JG, Treasure ET, O’Sullivan I, Morris J, Murray JJ: Adult Dental Health Survey 2009: transformations in British oral health 1968 2009. Br Dent J 2012;213:523-527.

Suominen-Taipale L, Nordblad A, Vehkalahti M, Aromaa A: Oral Health in the Finnish Adult Population. Health 2000 Survey. National Public Health Institute, Publications of the National Public Health Institute B 25/2008, 2008, pp. 3-93.

Tsakos G, Allen PF, Steele JG, Locker D: Interpreting oral health-related quality of life data. Community Dent Oral Epidemiol 2012;40: 193-200.

Tserakhava T, Shakavets N, Smirnoy A: Systems for the provision of oral health care in the Black Sea countries - Part 9: Belarus. OHDM 2011;10:3-6

Tseveenjav B, Suominen-Taipale L, Varsio S, Hausen H, Knuuttila M, Vehkalahti MM: Patterns of oral cleaning habits and use of fluoride among dentate adults in Finland. Oral Health Prev Dent 2010;8:287-294.

Tubert-Jeannin S, Riordan PJ, Morel-Papernot A, Roland M: Dental status and oral health quality of life in economically disadvantaged French adults. Spec Care Dentist 2004;24: 264-269.

Vrbic V: Reasons for the caries decline in Slovenia. Community Dent Oral Epidemiol 2000; 28:126-132.

WHO: Oral Health Surveys: Basic Methods, ed 2. Geneva, WHO, 2013.

WHO: Oral Health Country/Area Profile Programme (CAPP). Geneva, WHO Collaborating Centre, Malmö University, Sweden, 2014.

Yudina N, Rusak A, Yuris O, Brovka D, Shabunko D: Dental caries in adult people in Belarus. The 58th Annual ORCA Congress. Caries Res 2011;45:204.

Zitzmann NU, Staehelin K, Walls AWG, Menghini G, Weiger R, Zemp Stutz E: Changes in oral health over a 10 -yr period in Switzerland. Eur J Oral Sci 2008;116:52-59. 